\title{
BIOLOGI DAN DEMOGRAFI TUNGAU MERAH Tetranychus spp. (Acari: Tetranychidae) PADA TANAMAN KEDELAI
}

\author{
BIOLOGY AND DEMOGRAPHY OF RED SPIDER MITE Tetranychusspp. ( Acari: \\ Tetranychidae) ON SOYBEAN
}

\author{
J.M.E. Mamahit $\left.{ }^{\star}\right)$ \\ *Dosen Fakultas Pertanian Unsrat Manado
}

\begin{abstract}
Red spider mite Tetranychus spp. are pest on several ornament and food plant. The objectives of this research were to study biology and demography Tetranychus spp. on soybean in condition laboratory. A piece of soybean leaf measures $3 \mathrm{~cm} 2$ at place above cotton in petridis. Above the leaf were put a pair red spider mite to watch the biology of mite. The research of demography of red spider mite was done observation in one hundred egg that used to come from age class same (cohort). The observation was done every day until the egg become to adult. The result showed that the mean of fecundity of red spider mite were $54.16 \mathrm{egg}$. The total life time of female 13.28 day and sex ratio 1:1.5. The intrinsic rate of increase the population were 0.253 individual per day, the discrete daily growth rate were, 1.28 individual/day, the net reproduction rate were 25.515 individual/female/generation. The generation time were 13.567 days. The stable population of Tetranychus spp. in laboratory were $67.2 \%$ egg, 24.6 nymph and $8.2 \%$ adult. The intrinsic birth and death rate were 0.3 and 0.05 individual/female/day.
\end{abstract}

Key words: Tetranychusspp., Demography, Soybean

\section{ABSTRAK}

Tungau merah Tetranychus spp. merupakan hama yang banyak merusak tanaman pangan maupun tanaman hias dan sering menyebabkan kerusakan atau kematian pada tanaman inangnya. Tujuan penelitian ini adalah untuk mengetahui biologi dan demografi Tetranychus spp. pada kondisi di laboratorium dengan menggunakan daun kedelai sebagai pakan. Sepotong daun kedelai berukuran 3 $\mathrm{cm}^{2}$ di tempatkan di atas kapas pada cawan petri. Selanjutnya di atas daun pada tiap petri diletakkan sepasang tungau merah untuk diamati biologinya. Untuk penelitian demografi tungau dilakukan pengamatan pada seratus butir telur tungau yang digunakan berasal dari kelas umur yang sama (cohort). Pengamatan terhadap seratus butir telur tersebut dilakukan setiap hari sampai seluruhnya menjadi imago. Hasil penelitian menunjukkan rataan keperidian tungau adalah 54.16 butir telur, lama hidup imago betina 13.28 hari dan nisbah kelamin 1:1.5. Laju pertumbuhan intrinsik hama ini adalah 0.253 individu per induk per hari, laju pertumbuhan terbatas 1.288 individu per hari, laju reproduksi bersih 25.515 individu pe rinduk pergenerasi dan lama generasi adalah 13.567 hari. Puncak nilai reproduktif dimiliki oleh imago yang berumur dua hari. Sebaran umur stabil di laboratorium adalah $67.2 \%$ telur, $24.6 \%$ nimfa dan $8.2 \%$ imago. Laju kelahiran 0.30 individu per hari dan laju kematian 0.0501 individu per induk per hari.

Kata kunci: Tetranychusspp, Demografi, Kedelai 


\section{PENDAHULUAN}

Tungau merah Tetranychus spp. (red spider mite) termasuk hama yang tergolong dalam ordo Acari, famili Tetranychidae (Silva et.al., 2009; Kalshoven 1981). Tungau dapat menyerang pada beberapa tanaman antara lain: kapas, strowberi, tomat, kedelai, kacang panjang dan tanaman hias seperti bunga ros (Silva et.al., 2009). Larva Tetranychus spp. berwarna kuning kehijau-hijauan sedangkan yang dewasa berwarna hijau, kuning, oranye dan merah cerah dan biasanya ditemukan diantara jala-jala sutera halus yang dijalin oleh tungau ini dari kelenjar uniselular besar yang terletak di palpi. Tungau dewasa berukuran $\pm 1 \mathrm{~mm}$ (Kalshoven (1981).

Perkembangan Tetranychus spp. relatif cepat dan siklus hidupnya relatif singkat, tetapi keperidiannya tidak tinggi untuk golongan arthropoda. Oviposisi pada tetranychidae didahului oleh masa oviposisi yang singkat dan mencapai puncaknya secara cepat dan diikuti penurunan oviposisi secara perlahan (Huffaker et.al., 1969). Seekor betina akan menghasilkan sekitar 15-20 telur per hari. Karena jumlah generasinya yang tinggi dalam satu musim menyebabkan kerusakan yang ditimbulkannya juga besar.

Serangan tungau merah dapat merusak karena baik nimfa maupun imago mengisap cairan dari daun, cabang muda dan buah dari inangnya. Tungau merah juga mengeluarkan toksin pada waktu makan sehingga mengganggu proses metabolisme tanaman yang berakibat pada pengurangan serat, biji dan buah serta menyebabkan daun menjadi kuning, kering dan akhirnya daun gugur. Pada serangan yang berat dapat menyebabkan kematian tanaman. Cuaca dengan kombinasi suhu tinggi dan kelembaban yang rendah berkorelasi dengan meledaknya populasi tetranychid (Huffaker et.al., 1969). Tungau ini banyak ditemukan pada bagian permukaan daun, hidup berkoloni di bawah jaring yang dibuatnya (Silva et.al., 2009). Hama ini mengisap pada daun menyebabkan gejala klorotik pada daun dan gugur daun sehingga menurunkan buah yang dihasilkan. Menurut Fraulo et.al., (2007) pengendalian hama tungau merah Tetranychus spp. yaitu : menggunakan tungau predator yaitu: Phytoscilus persimis dan Neoseiulus californis. Untuk pengendalian tungau merah ini selain pengaturan populasinya dengan musuh alami, juga melalui pengaturan faktor-faktor yang mempengaruhi populasinya dengan memanipulasi lingkungan hidupnya yang kurang disukai oleh tungau tersebut.

Demografi merupakan analisis kuantitatif karakteristik populasi, khususnya hubungannya dengan pola pertumbuhan populasi, daya bertahan hidup dan perpindahan. Perubahan-perubahan numerik dalam populasi tersebut dapat digambarkan melalui laju kelahiran, laju kematian dan laju imigrasi. Kelahiran dan kematian dapat ditabulasi membentuk suatu neraca kehidupan (Price 1975).

Statistik demografi suatu hama dapat digunakan untuk menentukan faktor kritis populasi hama (Jones dan Sasaki 2001) serta untuk memahami pengaruh faktor-faktor eksternal terhadap agen pengendali biologi (Legaspi 2004). Selain itu pemahaman statistik demografi hama sangat penting untuk memprediksi perkembangan populasi hama dan pengembangan strategi pengendalian hama tersebut (Tsai dan Liu 2000). Pengetahuan tentang aspek biologi dan beberapa variabel laju pertumbuhan populasi hama tungau merah Tetranychus spp. dapat dipakai untuk informasi dalam usaha pencegahan dan pengendalian hama tersebut.

Perkembangan populasi dari Tetranychus spp. dapat dipahami dengan pendekatan neraca kehidupan, sehingga diperoleh informasi tentang proses perkembangan populasi dibawa kondisi lingkungan laboratorium. Meskipun kondisi tersebut jarang terjadi pada populasi alami, tetapi parameter populasi yang diperoleh pada percobaan laboratorium berguna dalam membandingkan demografi populasi yang berbeda, baik inter maupun intra-spesies.

\section{METODE PENELITIAN}

Penelitian ini dilaksanakan di laboratorium Ekologi Jurusan Hama dan Penyakit Pertanian Bogor dengan suhu kamar sekitar $25^{\circ} \mathrm{C}$. Percobaan ini diawali dengan menyiapkan cawan 
petri (diameter $6 \mathrm{~cm}$ ) yang didalamnya dimasukan busa karet (diameter $5,5 \mathrm{~cm}$ ) yang direndam dalam air. Di atas busa karet ditempatkan selapis kapas (diameter $4 \mathrm{~cm}$ ). Kapas diusahakan selalu direndam dalam air, hal ini untuk menghindari tungau keluar. Sebagai pakan tungau digunakan daun tanaman kedelai. Mula-mula benih kedelai ditanam dalam polibag. Tanaman kedelai yang tumbuh digunakan dengan mengambil daun ketiga atau keempat. Sepotong daun kedelai berukuran 3 $\mathrm{cm}^{2}$ di tempatkan di atas kapas pada cawan petri. Tungau merah diperoleh dari daun singkong yang terserang di lapang yang diperbanyak di laboratorium. Selanjutnya di atas daun pada tiap petri diletakkan sepasang tungau merah untuk diamati biologinya.

Telur yang digunakan untuk memulai percobaan diperoleh dengan memasukan masingmasing satu pasang imago Tetranychus spp. pada potongan daun dalam cawan petri. Setelah 24 jam betina dan jantan disingkirkan dan dihitung jumlah telurnya. Sebanyak seratus butir telur tungau yang digunakan berasal dari kelas umur yang sama (cohort). Pengamatan terhadap seratus butir telur tersebut dilakukan setiap hari sampai seluruhnya menjadi imago, meliputi jumlah pra dewasa dan dewasa yang masih hidup, mati dan nisbah kelamin. Potongan daun kedelai untuk pakan tungau diganti setiap tiga kali sekali. Perkembangan telur sampai menjadi imago dalam cawan petri diamati di bawah mikroskop.

Untuk mengamati keperidian harian betina dilakukan dengan meletakan sebanyak 25 imago betina stadium oviposisi (umur sama) secara individu pada potongan daun kedelai dalam cawan petri. Banyaknya telur yang di letakan diamati setiap hari dan lama hidup imago betina dicatat.

\section{HASIL DAN PEMBAHASAN}

\section{Biologi Tetranychusspp.}

Rata-rata lama praoviposisi, oviposisi, jumlah telur dan lama hidup imago betina Tetranychus spp. pada daun kedelai disajikan pada Tabel 1. Jumlah telur yang di letakan seekor betina selama hidupnya sekitar 54 butir dengan rata-rata jumlah telur yang diletakkan setiap hari sekitar 5 butir.

Nisbah kelamin Tetranychus spp. yang didapat dari percobaan ini adalah 0.60 , artinya $60 \%$ populasi berkelamin betina atau nisbah kelamin jantan dan betina 1:1.5. Huffaker et.al. (1969) menyatakan bahwa nisbah kelamin dari tetranichid belum diketahui, namun pada banyak populasi, jumlah betina umumnya lebih banyak daripada jumlah jantan. Nisbah kelamin dengan proporsi betina lebih tinggi akan menghasilkan keturunan dengan jumlah betina yang tinggi pula. Hal ini dimungkinkan karena populasi pada Tetranychus spp. terjadi sesaat setelah betina teliochryosalis menjadi imago betina, sehingga sebagian besar telur-telur dalam ovary dibuahi. Tetranychus spp. terjadi sesaat setelah betina teliochryosalis menjadi imago betina, sehingga sebagian besar telur-telur dalam ovary dibuahi. Tetranychus spp. seringkali didampingi oleh minimal seekor jantan sampai muncul menjadi imago betina. Telur-telur yang tidak dibuahi hanya menghasilkan jantan dan telur-telur yang dibuahi hanya menghasilkan betina. Tetapi betina yang kopulasi akan menghasilkan keturunan jantan dan betina karena tidak semua telur dibuahi. Menurut Silva (2009) siklus hidup hama ini juga bervariasi tergantung ada tidaknya pembuahan. Siklus hidup berkisar 21.65 hari dan 26.25 hari pada pembuahan dan tanpa pembuahan.

Tabel 1 Berbagai parameter biologi dari imago betina Tetranychus spp. pada kedelai (Table 1. Biologycal parameters from female Tetranychus spp. on soybean)

\begin{tabular}{lll}
\multicolumn{1}{c}{ Parameter Pengamatan } & \multicolumn{1}{c}{ Rataan \pm stdev } \\
\hline Rata-rata jumlah telur/betina/hari & 4.76 & \pm 1.9 \\
Jumlah telur yang di letakan setiap betina (butir) & 54.16 & \pm 14.06 \\
Periode praoviposisi (hari) & 0.95 & \pm 0.1 \\
Periode oviposisi (hari) & $11.56 \pm \pm 3.31$ \\
Lama hidup (hari) & $13.28 \pm 4.7$ \\
\hline Nisbah kelamin (jantan : betina) & $40: 60$ & \\
\hline
\end{tabular}


Sintasan (kemampuan hidup) tungau Tetranychus spp diperoleh dari pengamatan harian 100 butir telur sampai menjadi dewasa yang disusun dalam neraca kehidupan. Pengamatan menghasilkan data sintasan tungau Tetranychuc spp. pada berbagai umur (x). Untuk itu hasilnya dipaparkan pada gambar 1 (kurva atas). Dari kurva tersebut ternyata sintasan mulai menurun sejak berumur lima hari dan menurun terus sampai semua imagonya mati. Kurva tersebut memperlihatkan pola yang disebut tipe I, yaitu kematian yang rendah pada umur muda atau kematian meningkat dengan bertambahnya umur (Rauf \& Hidayat 1987, Tarumingkeng 1994). Pola ini umum ditemukan pada serangga yang dikurung sehingga terhindar dari berbagai gangguan luar. Kematian Tetranychus spp. pada fase telur sekitar $4 \%$, sedangkan pada fase nimfa sekitar $12 \%$. Guna menentukan parameter biologi lainnya perlu diketahui rata-rata keperidian betina yang hidup pada umur tertentu $\left(m_{x}\right)$. Karena sex rasio betina 0.6 sehingga nilai $m_{x}$ yang diperhitungkan adalah 0.6 dari jumlah telur yang diletakan. Gambar 1 (kurva bawah) memperlihatkan hubungan antara umur $(x)$ dengan $m_{x}$. Rata-rata keperidian $\left(m_{x}\right)$ betina mulai meningkat pada saat hari pertama imago betina dan puncak $m_{x}$-nya dicapai pada saat imago betina berumur sekitar 3 hari. Hasil ini menunjukkan bahwa tungau betina Tetranychus spp. meletakan sebagian besar telurnya lebih awal.

\section{Statistik Neraca Kehidupan}

Parameter populasi tungau Tetranychus spp. yang meliputi laju reproduktif kotor (GRR), laju reproduktif bersih $\left(R_{0}\right)$, lama generasi $(T)$, laju pertumbuhan intrinsic $(r)$, laju pertumbuhan terbatas $(\lambda)$, serta nilai reproduktif $\left(V_{x} / V_{0}\right)$ dihitung berdasarkan data $1_{\mathrm{x}}$ dan $\mathrm{m}_{\mathrm{x}}$. Nilai parameter tersebut terlihat pada Tabel 2 dan Gambar 2.

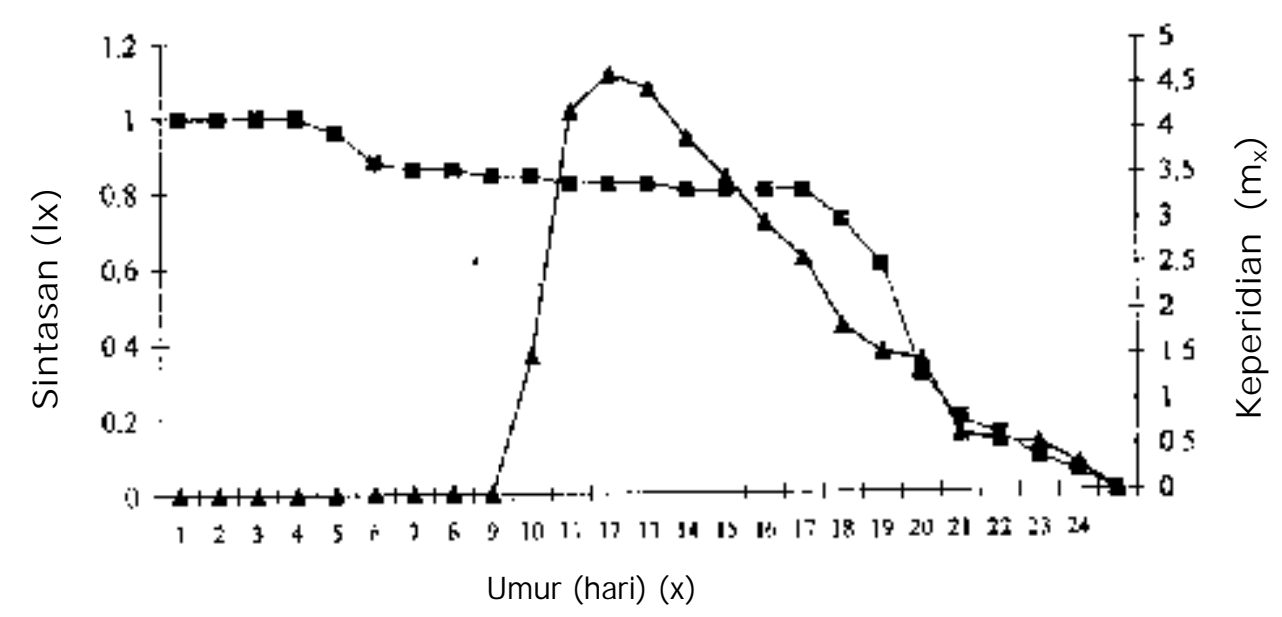

Gambar 1. Kurva Hubungan antara umur Tetrasnychus spp dengan sintasan dan keperidian (Figure 1. The relation of age, survivorship and fecundity curves of Tetrasnychus spp.)

Tabel 2. Parameter yang berkaitan dengan potensi laju pertumbuhan populasi Tetranychus spp. (Table 2. The Parameter of Potential Growth Population of Tetranychus spp.)

\begin{tabular}{cc} 
Parameter & Nilai \\
\hline GRR & 34.638 \\
Ro & 25.515 \\
$R$ & 0.25314 \\
$\lambda$ & 1.288 \\
T & 13.567 \\
B & 0.3032 \\
d & 0.0501 \\
\hline
\end{tabular}




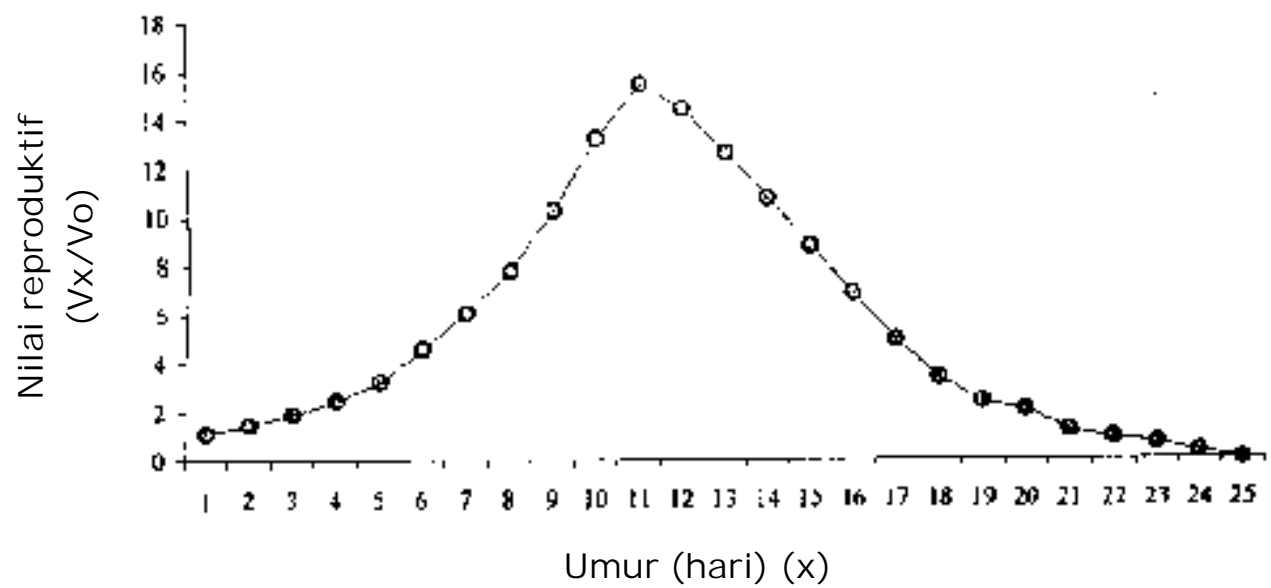

Gambar 2. Kurva Hubungan antara umur Tetrasnychus spp. dengan nilai reproduktif

(Figure 2. The relation of reproduction value and age curve of Tetrasnychus spp.)

Laju reproduktif kotor (GRR) adalah ratarata jumlah keturunan betina per induk per generasi $\left(\sum m_{x}\right)$, sedangkan laju reproduktif bersih $\left(R_{0}\right)$ menunjukan jumlah keturunan betina yang berhasil menjadi imago $\left(\left.\Sigma\right|_{x} m_{x}\right)$. Nilai $R_{0}(25.515)$ lebih rendah dari pada GRR (34.638) karena nilai $\left(\mathrm{R}_{0}\right)$ telah mempertimbangkan jumlah individu yang hidup $\left(\mathrm{I}_{\mathrm{x}}\right)$.

Laju pertumbuhan intrinsik ( $r$ ) menggambarkan laju pertumbuhan populasi pada keadaan lingkungan konstan, sumber daya tak terbatas serta kematian yang terjadi hanya disebabkan oleh faktor fisiologi (Birch 1948). Nilai $r$ dihitung berdasarkan rumus: $\sum e^{-r x} x_{x} m_{x}=1$. Diantara nilai parameter biologi lainnya, nilai $r$ merupakan statistik yang berguna untuk membandingkan laju pertumbuhan populasi dari spesies berbeda atau laju pertumbuhan populasi dari spesis yang sama tetapi dengan kondisi lingkungan yang berbeda (Price, 1997). Nilai r untuk tungau Tetranychus spp. yaitu 0.25314 betina per induk per hari. Nilai $r$ dari tungtau Tetranychum spp. hampir sama dengan nilai $r$ dari tungau Tetranichydae lainnya seperti Panonychus citri yaitu 0.2 betina per induk per hari (Puspitorini et.al., 2003) dan T. urticae sekitar 0.12 betina per induk per hari (Silva 2009). Laju pertumbuhan terbatas $\left(\lambda=\mathrm{e}^{-r}\right)$ dari Tetranychus spp. adalah 1.288. Hasil penelitian ini menyerupai hasil penelitian Silvia et.al. (2009) yang menemukan $\lambda$ dari $T$. urticae sekitar 1.13-1.19.
Nilai ini menunjukan kelipatan populasi Tetranychus spp. per hari.

Rata-rata lama generasi $(\mathrm{T})$ Tetranychus spp adalah 13.567 hari. Lama generasi menunjukan bahwa dalam waktu 13.567 hari betina Tetranychus spp. yang muncul menghasilkan keturunan lagi. Lama generasi tergantung pada tanaman inangnya. Menurut penelitian Silva et.al. (1987) dalam Silva et.al. (2009) lama generasi Tetranychus spp. pada tanaman kapas dan kacang panjang berkisar 22.2 dan 24.9 hari.

Nilai reproduktif yang dikembangkan oleh (Fisher 1930 dalam Wilson \& Bossert 1971) digunakan untuk mengukur sumbangan relative dari individu berumur $x$ terhadap generasi berikutnya. Hasil perhitungan $V_{x} / V_{0}$ untuk Tetranychus spp ditampilkan pada Gambar 2. Jumlah total nilai reproduktif untuk seluruh umur adalah 136.213. Nilai reproduktif tertinggi dimiliki oleh individu yang berumur 10 hari atau imago berumur dua hari, yaitu satu hari sebelum jumlah telur yang diletakan per hari mencapai maksimum. Nilai reproduktif merupakan faktor utama dalam keberhasilan kolonisasi. Species migran yang berhasil mengkolonisasi habitat baru cenderung memiliki mobilitas dan nilai reproduksi yang tinggi dari pada yang memiliki nilai rendah (Wilson \& Bossert, 1971). Diduga populasi awal Tetranychus spp. yang pertama kali tiba di Indonesia merupakan imagoimago muda yang memiliki kemampuan memencar dan nilai reproduktif yang tinggi. Meskipun tidak 
bersayap Tetranychus spp. dapat memencar ke tajuk tanaman melalui ballooning dengan benang sutera yang digunakan sebagai parasut sehingga mudah terbawa angin (Huffaker et al. 1969).

\section{Sebaran Umur Stabil}

Sebaran umur stabil (Px) menunjukan proporsi individu-individu yang berumur $\mathrm{x}$ dari populasi yang meningkat dengan konstan, yang diperoleh dengan rumus: $P x=100 \beta 1 \times \mathrm{e}^{-\mathrm{r}(x+1)}$ dan $1 / \beta=\Sigma 1 \times \mathrm{e}^{-r(x+1)}$. Untuk memudahkan penafsiran, parameter ini disusun sesuai fase perkembangan tungau. Berdasarkan data neraca kehidupan di laboratorium sebaran umur stabil dari Tetranychus spp. adalah $67.2 \%$ telur, $24.6 \%$ nimfa dan $8.2 \%$ imago. Keadaan stabil ini adalah prasyarat bagi tercapainya laju pertumbuhan 0.25341 per induk per hari.

Angka kelahiran (b) Tetranychus spp yaitu 0.30 individu per induk per hari. Angka kematian (d) Tetranychus spp yang diberi pakan daun kedelai pada pemeliharaan di laboratorium dengan suhu rata-rata $25^{\circ} \mathrm{C}$ yaitu 0.0501 individu per induk per hari. Angka kematian ini sangat dipengaruhi oleh suhu dan kelembaban laboratorium dan pakannya. Di alam kematian banyak terjadi oleh tingginya curah hujan dan adanya musuh alami seperti predator. Kematian Tetranychus spp dari percobaan ini sangat dipengaruhi oleh umur. Semakin tinggi umur Tetranychus spp. semakin meningkat mortalitasnya atau kurva sintasan termasuk pada Tipe 1. Menurut Silva et.al. (2009) mortalitas tungau selain dipengaruhi oleh kondisi pakan untuk tungau juga dipengaruhi oleh kondisi temperatur di laboratorium.

\section{KESIMPULAN}

Rataan keperidian Tetranychus spp adalah 54.16 butir telur, lama oviposisi 11.56 hari, lama hidup 13.28 hari dan nisbah kelamin jantan dan betina adalah 1:1.5. Laju pertumbuhan intrinsik Tetranychus spp adalah 0.25314 individu per induk per hari, laju pertumbuhan terbatas 1.288 individu per hari, laju reproduksi bersih 25.515 individu per induk per generasi dan lama generasi adalah 13.567 hari. Puncak nilai reproduktif dimiliki oleh imago yang berumur 2 hari. Sebaran umur stabil adalah $67.2 \%$ telur, $24.6 \%$ nimfa dan $8.2 \%$ imago. Mortalitas meningkat dengan bertambahnya umur atau kurva sintasan Tetranychus spp. termasuk Tipe 1.

\section{DAFTAR PUSTAKA}

Fraulo, A. B. and O. E. Liburt. 2007. Biological Control of Two Spotted Spider Mite Tetranychichus urticae with Predatory Mite Neoseilus californicus in Strawberries. Exp. App. Acarol. 43: 109-119.

Huffaker, C.B., Vrie M van de \& J.A. McMurtry. 1969. The Ecology of Tetranychid Mites and Their Control. Ann. Rev. Entomol. 14:125-174

Jones V.P., Sasaki MA. 2001. Demographic Analiysis of Delayed Mating Disruption: A Study with Criptophelbia illepida (Lepidoptera: Tortricidae). J. Econ. Entomol 94(4):785-792.

Ikegami.Y.S. Yano, J.Takabayashi and A. Takafuji. 2000. Function of Quiescense of Tetranychus kanzawai (Acari: Tetranvchidae) as a Defence Mechanism Agains Rain. Appl. Entomol. Zool. 35:339343

Kalshoven. L.G.E. 1981. Pest of Crops in Indonesia. Revised and Translated by P.A. van der Laan. P.T. Ichtiar Baru van Hoeve.

Legaspi J.C. 2004. Life History of Podisus maculifentris (Heteroptera: Pentatomidae) Adult Females Under Different Constant Temperatures. Envir. Entom. 33 (5): 12001206.

Price, P.W. 1997. Insec Ecology. Thirt edition. John Wiley\&Sons. Inc. $874 \mathrm{p}$

Puspitorini, R.D., Rauf, S. Sosromarsono \& T. Santoso 2003. Biologi dan Demografi Tungau Merah. Institut Pertanian Bogor.

Rauf, A dan P. Hidayat 1987. Statistik Demografi Kutu Loncat Lamtoro Heteropsylla cubana Crawford (Homoptera, Psyllidae). Jurusan Hama dan Penyakit Fakultas Pertanian Bogor. 
Silva, E.A, Reis P.R., Carvalho, T.M.B and B.F. Altoe. 2009. Biology Tetranichus urticae (Acari: Tetranychidae) on Gerbera jamesonii Bolus and Hook (Asteraceae). Braz. J. Biol. 69(4): 1121-1129

Tarumingkeng, R.C. 1994. Dinamika Populasi Kajian Ekologi Kuantitatif. Pustaka Sinar Harapan dan Universitas Kristen Krida Wacana. Jakarta..
Tsai JH, Liu YH. 2000. Biology of Diarphorina citri (Homoptera: Psillidae) on Four Host Plant. $J$ Econ Entom 93(6): 1721-1725.

Wilson, E.O. \& H.W. Bossert, 1971. A Primer of Popilation Biology. Sinauer Assosiates Inc Publisher. Sunderland, Massachusetts 01375

Vri, van vrie M, J.A. McMurtry, C.B. Huffaker, 1972. Biology, Ecology and Pest Status and Host-Plant Relation of Tetranychids. Hilgardia 41:343-432. 
